\title{
Analysis of the Main Influencing Factors for Population Density Based on the Method of Gray Correlation Analysis
}

\author{
Yu Xia, Cheng Wang* \\ School of Mathematics and Economics, Hubei University of Education, \\ Wuhan 430205, P. R. China \\ *Corresponding Author: wangc80@163.com
}

\begin{abstract}
Keywords: Population density; Gray correlation analysis; Main influencing factors.
Abstract. Aiming at analyzing the main factors which may influence the population density, this paper establishes a gray correlation analysis method to determine the main influencing factors for population density of Wuhan City according to the data in the statistical yearbook of Wuhan City. The result shows that GDP, employment quantity and completed area of housing construction are the three main factors which affect the population density of Wuhan City.
\end{abstract}

\section{Introduction}

In 2015, with the rapid development of Optics Valley's economy, as GDP accounted for 70\% of Wuhan's population, has been ranked 1 million 500 thousand at Optics Valley GDP in Wuhan accounted for half of the country, the proportion will further expand in the future, it is expected that in 2019, the "big Optics Valley" total output value will exceed 1 trillion yuan of industrial sector. Huge economic strength and sufficient talent reserves, Optics Valley has become increasingly dazzling.

In this paper, we take the region area and population density as the research object, and focus on the the factors such as Wuhan GDP, employment quantity and completed area of housing construction [1-4], then we establish a gray correlation analysis method [5-8] to determine the main influencing factors for population density of Wuhan City according to the data in the statistical yearbook of Wuhan City.

\section{Correlation Analysis on Various Factors Affecting Population Density}

Gray relational principle. Let $X=\left\{x_{0}, x_{1}, \mathrm{~L}, x_{m}\right\}$ be a gray correlation factor set, $x_{0}$ be a reference sequence, and $x_{i}$ be the compare sequences, $i=\{1,2, \mathrm{~L}, m\}, x_{0}(k), x_{i}(k)$ respectively, and $x_{0}$ and $x_{i}$ be the number of $k$ points, that is

$$
\begin{aligned}
& x_{0}=\left(x_{0}(1), x_{2}(2), \mathrm{L}, x_{0}(n)\right), x_{1}=\left(x_{1}(1), x_{1}(2), \mathrm{L}, x_{1}(n)\right), x_{2}=\left(x_{2}(1), x_{2}(2), \mathrm{L}, x_{2}(n)\right) \\
& \cdots \ldots \\
& x_{m}=\left(x_{m}(1), x_{m}(2), \mathrm{L}, x_{m}(n)\right),
\end{aligned}
$$

if

$$
r\left(x_{0}, x_{i}\right)=\sum_{k=1}^{n} \omega_{k} r\left(x_{0}(k), x_{i}(k)\right) \quad r\left(x_{0}(k), x_{i}(k)\right)=\frac{\Delta_{\min }+\rho \Delta_{\max }}{\Delta_{0 i}(k)+\rho \quad \Delta_{\max }}
$$

where $\Delta_{0 i}(k)=\left|x_{0}(k)-x_{i}(k)\right|$ is the absolute difference, $\Delta_{\min }=\min _{i} \min _{k} \Delta_{0 i}(k)$ is the smallest difference between the poles, $\Delta_{\max }=\max _{i} \max _{k} \Delta_{0 i}(k)$ is the maximum difference for the poles, $\rho$ is the distinguish between coefficients $(\rho$ in the above theorem in the actual calculation of the general is 0.5$). \omega_{k}$ is the $k$-point weight, which satisfies $0 \leq \omega_{k} \leq 1, \sum_{k=1}^{n} \omega_{k}=1$, then we call $r\left(x_{0}(k), x_{i}(k)\right)$ is the gray correlation coefficient for $x_{0}$ and $x_{i}$, and $r\left(x_{0}, x_{i}\right)$ is the gray relation degree of $x_{0}$ and $x_{i}$. 
In general, when $r\left(x_{0}, x_{i}\right)>r\left(x_{0}, x_{j}\right)$, which means the gray correlation degree between $x_{i}$ and $x_{0}$ is higher than that between $x_{j}$ and $x_{0}$, or the influence degree of $x_{i}$ on $x_{0}$ is greater than the influence degree of $x_{j}$ on $x_{0}$.

Gray Relational Analysis on Factors Affecting Population Density. Let $x_{1}, x_{2}, x_{3}, x_{4}, x_{5}, x_{6}, x_{7}, x_{8}$ represent the annual average temperature in Wuhan City, employment quantity, and completed area of housing construction, the green coverage rate of built-up areas, the mass production of public transportation vehicles, high-tech industries per 10,000 population, road area and annual GDP.

(1) Data collection and analysis

The statistics of various factors that affect the population density can be obtained by referring to Wuhan Bureau of Statistics [3] as shown in Table 1 below.

Table 1. 2010-2015 Factors statistics for population density in Wuhan City

\begin{tabular}{|c|c|c|c|c|c|c|}
\hline $\begin{array}{l}\text { Employment quantity } \\
\text { (million) }\end{array}$ & 483 & 498 & 506.4 & 522.24 & 530.44 & 544.92 \\
\hline $\begin{array}{l}\text { Completed area of housing } \\
\text { construction }(10,000 \text { square } \\
\text { meters })\end{array}$ & 5664.39 & 8114.17 & 9223.5 & 10103.98 & 10223.95 & 11958.87 \\
\hline $\begin{array}{c}\text { Built-up area green coverage } \\
(\%)\end{array}$ & 37.17 & 37.59 & 38.19 & 38.2 & 39.21 & 39.65 \\
\hline $\begin{array}{l}\text { Every } 10,000 \text { people have } \\
\text { public transport vehicles } \\
\text { (standard) }\end{array}$ & 15.5 & 15.2 & 14.2 & 13.9 & 16.2 & 13.8 \\
\hline $\begin{array}{l}\text { The total output of high-tech } \\
\text { industry development } \\
\text { (million) }\end{array}$ & 26380353 & 34489139 & 45560041 & 56044728 & 65996966 & 74992058 \\
\hline $\begin{array}{l}\text { Road area (million square } \\
\text { meters) }\end{array}$ & 7273 & 7726.2 & 9027.2 & 8384 & 8879.63 & 9495 \\
\hline Annual output value & 5565.93 & 6762.2 & 8003.82 & 9051.27 & 10069.48 & 10905.6 \\
\hline
\end{tabular}

(2) Analyze the factors affecting population density by gray relational analysis method

We take the population density as a reference sequence $x_{0}(k), k=1, \mathrm{~L}, 6$, other factors as the comparative factor sequences $x_{i}(k), i=1, \mathrm{~L}, 8 ; k=1, \mathrm{~L}, 6$, the specific calculation process of gray correlation analysis is as follows:

Step 1: Data standardization. Initialization of the various factors, the standardization of the sequence $y_{i}(k), i=0,1, \mathrm{~L}, 8 ; k=1, \mathrm{~L}, 6$, and dimensionless sequence, as shown in Table 2 below.

Table 2. Various factors data series

\begin{tabular}{|c|c|c|c|c|c|}
\hline Factors & 2010 & 2011 & 2012 & 2013 & 2014 \\
\hline Population density (person / km2) & 1.0000 & 1.0010 & 1.1992 & 1.2104 & 1.2226 \\
\hline $\begin{array}{l}\text { Average annual temperature } \\
\text { (degrees Celsius) }\end{array}$ & 1.0000 & 0.9819 & 0.9879 & 1.0301 & 1.0060 \\
\hline Employment quantity (million) & 1.0000 & 1.0310 & 1.0484 & 1.0812 & 1.0982 \\
\hline $\begin{array}{c}\text { Completed area of housing } \\
\text { construction }(10,000 \text { square } \\
\text { meters })\end{array}$ & 1.0000 & 1.4324 & 1.6283 & 1.7837 & 1.8049 \\
\hline Built-up area green coverage (\%) & 1.0000 & 1.0112 & 1.0274 & 1.0277 & 1.0548 \\
\hline $\begin{array}{l}\text { Every } 10,000 \text { people have public } \\
\text { transport vehicles (standard) }\end{array}$ & 1.0000 & 0.9806 & 0.9161 & 0.8967 & 1.0451 \\
\hline $\begin{array}{l}\text { The total output of high-tech } \\
\text { industry development (million) }\end{array}$ & 1.0000 & 1.3073 & 1.7270 & 2.1244 & 2.5017 \\
\hline Road area (million square meters) & 1.0000 & 1.0623 & 1.2411 & 1.1527 & 1.2209 \\
\hline Annual output value & 1.0000 & 1.2248 & 1.4509 & 1.6409 & 1.8255 \\
\hline
\end{tabular}




\section{Step 2: Calculate the absolute difference}

Calculate the absolute difference based on the data in above Table 2 by the formula $\Delta_{i}(k)=\left|y_{0}(k)-y_{i}(k)\right|$, the result is as follows.

$\Delta_{1}=(0,0.0191,0.2113,0.1803,0.2166,0.2136)$

$\Delta_{2}=(0,0.0300,0.1508,0.1292,0.1244,0.0975)$

$\Delta_{3}=(0,0.4314,0.4291,0.5733,0.5823,0.8856)$

$\Delta_{4}=(0,0.0102,0.1718,0.1827,0.1678,0.1589)$

$\Delta_{5}=(0,0.0204,0.2831,0.3137,0.1775,0.3353)$

$\Delta_{6}=(0,0.3063,0.5278,0.9140,1.2791,1.6171)$

$\Delta_{7}=(0,0.0613,0.0419,0.0577,0.0017,0.0799)$

$\Delta_{8}=(0,0.2238,0.2517,0.4305,0.6029,0.7606)$

Obviously, we have

$\Delta_{\text {min }}=0, \Delta_{\text {max }}=1.6171$

\section{Step 3: Calculate the correlation coefficient.}

The correlation coefficient is calculated from the calculation result of Step2 as follows.

We set $\rho=0.5$, then we have

$$
\xi_{i(k)}=\frac{0+0.5 \times 1.6171}{\Delta_{i}+0.5 \times 1.6171} \text {. }
$$

Substituting the data in Table 2 into this formula, we can directly calculate the correlation coefficient, the result is as follows.

$$
\begin{aligned}
& \xi_{1(k)}=(1,0.976903,0.782821,0.817694,0.788743,0.791020) \\
& \xi_{2(k)}=(1,0.964242,0.842821,0.862254,0.866704,0.892380) \\
& \xi_{3(k)}=(1,0.652090,0.653286,0.585105,0.581317,0.477361) \\
& \xi_{4(k)}=(1,0.987562,0.824767,0.815714,0.828168,0.835745) \\
& \xi_{5(k)}=(1,0.975371,0.740675,0.720293,0.820020,0.706860) \\
& \xi_{6(k)}=(1,0.725263,0.605036,0.469380,0.387292,0.333333) \\
& \xi_{7(k)}=(1,0.929545,0.950717,0.933427,0.997949,0.910077) \\
& \xi_{8(k)}=(1,0.783224,0.762592,0.652537,0.572833,0.515280)
\end{aligned}
$$

\section{Step 4: Calculate the gray correlation degree and analyze the dominant factors}

Take $\omega_{k}=\frac{1}{6}$, then compare factor $x_{i}$ and reference factor $x_{0}$, the gray correlation degree $r_{i}$ is

$$
r_{i}=\frac{1}{6} \sum_{k=1}^{6} \xi_{i}(k) .
$$

Substituting the data in Table 2 into this formula, we can directly calculate the result as follows. 


$$
r_{1}=0.8612, r_{2}=0.9047, r_{3}=0.8820, r_{4}=0.6582, r_{5}=0.8272, r_{6}=0.5867, r_{7}=0.9536, r_{8}=0.7144 \text {. }
$$

By comparison, we have

$$
r_{7}>r_{2}>r_{3}>r_{1}>r_{5}>r_{8}>r_{4}>r_{6}
$$

Obviously, Wuhan's annual GDP has the greatest impact on population density, followed by the employment quantity and the completed area of housing construction. Therefore, these three factors are the main factors affecting population density in Wuhan City.

\section{Conclusions}

In this paper, we use quantitative method to present a number of factors that affect the population density, and then use gray relational analysis to quantitatively analyze and extract three main factors. This combination of qualitative and quantitative ideas has some new ideas, it is worth promoting. Optics Valley region has developed rapidly in recent years, so relative to the data of previous years, the data in recent years can better reflect the future development of the region. In order to make the model more reasonable, we can change the weight of the calendar year from when calculating the correlation coefficient, and then calculate the correlation coefficient to give the most relevant factors.

\section{Acknowledgments}

This work is supported by the 2017 Excellent Youth Project of Hubei Provincial Department of Education (No. Q20173007).

\section{References}

[1] Z.Q. Luo: Derivation and Application of Arbitrary Polygon Area Formula (University of Electronic Science and Technology of China, Chengdu 2005).

[2] Y. Gao: Simulation of Downscaling of County Population Density Based on GIS Data (China's Population, Resources and Environment 2017).

[3] Wuhan Statistical Yearbook on http://www.whtj.gov.cn/

[4] M. Grove: Population density, mobility, and cultural transmission, Journal of Archaeological Science 74 (2016) 75-84.

[5] Y.H. Liu, C.C. Gao and Y.Y. Lu: The impact of urbanization on GHG emissions in China: The role of population density, Journal of Cleaner Production 157 (2017) 299-309.

[6] C.J. Rao, X.P. Xiao, M. Goh, J.J. Zheng and J.H. Wen: Compound mechanism design of supplier selection based on multi-attribute auction and risk management of supply chain, Computers \& Industrial Engineering 105 (2017) 63-75.

[7] M.M. Rahman: Do population density, economic growth, energy use and exports adversely affect environmental quality in Asian populous countries? Renewable and Sustainable Energy Reviews 77 (2017) 506-514.

[8] C.J. Rao, M. Goh, Y. Zhao and J.J. Zheng: Location selection of sustainability city logistics centers, Transportation Research Part D: Transport and Environment 36 (2015) 29-44. 